\title{
Methods of Teaching and their Impact on Learn
}

\author{
Elida Kurti \\ Academical Editor at UET PRESS European University of Tirana, Faculty of Education and Social Sciences \\ Tirana/ Albania; Email: elida8010@hotmail.com
}

Doi:10.5901/mjss.2016.v7n1p489

\section{Abstract}

\begin{abstract}
This study highlights the role and importance of teaching where the student is in focus in our basic education, some of the phenomena that accompany the learning process and education, as well as expressing some inherent considerations about ways, techniques and the most effective forms of teaching-centered nowadays student. To achieve the main goal of this work and to achieve the objectives set, except for the use of an extensive literature contemporary in the field of teaching, I researched own material by interviewing students, parents and teachers as well as doing surveys with them. As primary sources were interviews, observations, questionnaires and surveys that are structured and semi-structured. Instruments of this survey are development of quantitative and qualitative measurement, in a word mixed methods. To understand better the functioning of teaching methods and their effect on the learning process was followed and observed classes in institutions designed to observe. The process of data and processing were conducted through three instruments: review of the literature, direct observation and questionnaires. The main object of this paper is to: - To make an interpretation of the method of student - centered teaching, which is the most efficient and most used by teachers. - To discern the current situation of these teaching methods, as aligned with European standards, which are the possible solutions to these schools and the premise to create a much more effective teaching. So I think that this paper is an attempt to distinguish some of the causes that lead to malfunctioning of our learning process in basic education, and to suggest some ways and forms a much more contemporary teaching.
\end{abstract}

Keywords: learning process, education, methods, students, contemporary teaching

\section{Introduction}

In the "Dictionary of education" (Grillo. K p:182) instruction is defined as the act of teaching in an educational institution; It is the operation and management of the learning process by the teacher. Teaching has always been a deliberate process, which should be implemented certain objectives. Like any deliberate act, teaching does not happen by chance, it is a planning process, requiring the effective implementation of this process. Teaching is: a) the transmission of knowledge from teacher to pupil, accompanied by the question "What?" - What to teach him; b) organization and direction of the work of students, accompanied by the question "How?" and facilitation of learning (What will teach and how to teach the student?).

Learning activities of students marks to achieve recognition. It is a process motivated and deliberate, the result of the skills many, such as: ability to convince yourself that learning is a duty personal skills to motivate yourself positively, the skills to plan time, skills to master the environment examines the skills to plan activities, ability to work alone or in groups, the skills to become aware of the results obtained, aiming to prepare to deliver a critical attitude toward what you learn, then start to himself. Learning is a phenomenon with personal character. Learning is so important to human life that it is hard to find a situation where it is not included. Often, teachers and school practice especially new teachers, and very difficult to orient themselves in unforeseen problems and situations related to pupils. This impels them to find the most appropriate solution. This fact is the source of many ideas and conceptions about learning and teaching.

Teaching, in the strict sense is the act of teaching in an educational institution. The process of teaching is one of the most important factors and most influential in achieving learning goals. Teaching helps students learn. Given this, some describe teaching as a process, as an action or an interpersonal activities, where the teacher interacts with one or more students and influence them, but that does not understand the impact of student to teacher. (Manual, Group of authors, 1999 p.20). In the broadest sense, teaching is the direction from the teacher in the learning situation and learning that includes:

a) proactive process of decision-making for planning, drafting and preparation of materials for teaching and learning, for diagnosing the needs of students, creating learning environment for the use of instructional time. 
b) the process interactive, direct cooperation of teacher-student, using the forms, methods and means of teaching.

c) prospectively process, summarizing evaluation, self-assessment, establishing procedures to evaluate learning, to put grades to assess the curriculum, to evaluate teaching materials.

So, teaching marks the teacher's activity. It is a set of strategies, tactics and pedagogical procedures teacher uses to teach students. Also, it is said that teaching is an intentional process, which means that this process is intended to be achieved certain goals, always oriented learning. (Ibid, p.22)

Learning and teaching are two basic processes that underlie the activities of students and teachers. Learning is the activity of the students, which is a phenomenon with individual character. Teaching is the direction of teacher learning situation and learning. Given that each student has its own uniqueness and learning, we cannot claim absolute recipes in his learning. Teachers can help students to choose the best method of learning. The learning process cannot be understood only in the capture of information, which remains just under reproduction information. Acquisition of real information will note only if we have the answer of the subject to students learning situation, whether there will be a sense or awareness of this new behavior, which leads to a conception on the part of students. Man undergoes changes throughout life, are the consequences of learning in turn, learning from educational institution and educational and learning from Micro-social.

Traditional pedagogy is taking time to determine the way in which concrete behavioral changes, taking into account teaching, as well as learning. Given this, professors and philosophers have made radical reforms in the structure of the school and its contents, which were spread throughout the world. Learning has attracted the attention of many researchers, education professionals and teachers. Special attention was paid to learning techniques in school, as an activity typically noted for individual, hence the necessity of knowledge and mastery of techniques to realize learning as a way that facilitates teaching and consequently that of learning.

Teaching cannot be defined simply as a set of methods. It means the fulfillment of a number of objectives for a particular group of students. Teaching must find the balance between teaching and leadership activities directly to students working on their own or in groups. Good teaching means to achieve the student develop skills and learning strategies, and simultaneously learn both what features matter. Although teaching is more than a set of strategies, some of the teaching methods should be part of the repertoire of every teacher.

\section{The Development of Critical Thinking among Students}

The essential characteristic, which is the heart of productive teaching, belongs to the development of critical thinking. It is considered as the basic pillar of modern teaching, on which is predicted the realization of educational activities. Changes or reforms that have begun to be practiced in education, require the students to establish the development of the information, while the teacher is considered as the main guide, which directs the activity in class by telling students the main road towards new researches. So, this tendency manifests itself with the methodology of teaching, which is called "student-centered teaching." Developing critical thinking is essential for students, and the only assistant who can grow it, is the teacher. (Guideline 1, AEDP 2000 :) No rule or typesetting of thoughts of thoughts and ideas from any group of people, cannot tell what is the best idea in a certain circumstance. The work done during the common interaction is done to improve the student's learning, which should be sustainable and should last for a lifetime. There has been written much about critical thinking. For people who think critically, meaning information base is a starting point more than the end of learning. The development of critical thinking critically involves the absorption of ideas and reviews their impact, presenting them in a sophisticated way to balance their opposing views in opposite, building reliable systems to try them out and take a sustainable base on these structures. Critical thinking is a complex process involving ideas and creative resources, the re-conceptualization and restructuring concepts and information. It is a cognitive, active and interactive process, which occurs simultaneously in many levels of thinking. Thinking is often inclined towards the goal, but it can also be a creative process, where the goals may be vague. Critical thinking is a very sophisticated way of thinking. It occurs in those cases when the older students should be. But even young students are fully able to engage in appropriate levels of development of critical thinking. They include optional tasks to solve difficult problems and to display higher levels of thinking on issues related to decision-making.

\subsection{What is critical thinking?}

Thinking is a similar process as reading, writing, speaking or listening. It is an active, interacting and complex process, which includes thinking about something real. In school, learning critically is better learned while testing it as a way of 
acquisition of content, as something that is part of the overall results. Actually, recent researches about critical thinking and learning model suggests us that the focused method reduces the development of critical thinking. For example, Brown (1989) argued that learning skills, shared objectives and real-world tasks, enable students to perform an objective test well, but they are unable to apply these skills to new situations. Richer definitions for learning and thinking are supported by researchers of cognitive psychology (cognitive), philosophy and multicultural education. The most common side in this research study are:

- Fruitful and long learning, which can be applied to new situations is a matter in whose information and ideas, have an important meaning. This happens when students energize in learning, enter inside learning and synthesize \& produce information by theirselves. (Anderson et.al, 1985).

- Students learning expands when there are used strategies for thinking. But even students should do their part in the learning process to have the required results. (Palinskar and Brown, 1989).

- Learning and critical thinking are expanded when students have the opportunity to apply new learning in the real tasks (Resnik 1987). Learning expands when it is built on previous knowledge and on the experience of the students (Roth 1990). Critical thinking and learning occurs when teachers understand and appreciate differences of ideas and experiences. Also critical thinking mentality occurs when "only one question is right" (Benks.1988).

Teaching for critical thinking is not a simple task or a task that can be performed in a certain class and then forgotten. Also there are not resolved steps in which the students and the teacher should walk along. However, there are some rules which promote the development of critical thinkers. Conditions which are described below are essential to promote critical thinking:

- Provide time and a chance to show critical thinking experiences.

- Create opportunities for students to think more about certain issues.

- Consider ideas ,thoughts and opinions.

- Encourage the active involvement of students in the learning process.

- Make sure the students to have a safe environment in which they do not have doubts that anyone could tease them.

- Express conviction in the ability of each student to make critic judgments.

- Appreciate the critical opinion expressed by students.

Critical thinking for various reasons takes a lot of time. Before thrown a hypothesis, first there is required time to discover what you think and how you are convinced in the topic.

The discovery of one's thoughts summarizes some "archaeological" ideas, beliefs, endeavors and experiences (Pearson, Hensen, Gordon 1979).

Time is also needed to start the expression of opinions by the students in their own words and to hear their speech and expression of ideas. But while, we must recognize that the exchange of ideas and critical thinking also requires time. Without this exchange it is not possible to assess or comment on the results of others, who are able to process thoughts and to reflect further. To promote critical thinking in the classroom, students should be given enough time to express their ideas and comments. During time spent in expressing thoughts in an environment which fosters the exchange of ideas, you should create opportunities for them to express themselves more clearly. Students do not always think freely and seriously about important issues. They often expect the teacher to determine "the only real answer." Students put together their own ideas and concepts in different ways. Some of these combination may be more productive than others, some may seem reasonable at first, but thinking further, they become less meaningful, or other definitions may seem stupid at first, but to make valid, they require processing. For this to happen, students should be given permission for this kind of thinking in order to create and express a clear opinion or "stupidity". When students understand the idea or thought, they are eligible to be involved more deeply in a critical analysis which can be required after. When teachers will give permission to students to deepen to their thinking and to become critical thinkers, they must do so by being under the control of their teacher. But even here we must distinguish between the provision of permit and being allowed. When students do not lack in the issue even the critically thinking will lack. Enough students come to school as slack students believing that the teacher and text contain knowledge and the teacher and text are responsible for their own learning. They see knowledge as immutable, that only need "to be emptied" by the teacher in their heads and reproduce command to show learning by reproducing knowledge. This suggestively learning shows that students are not involved in the process of developing critical thinking. Involvement in the process of developing critical thinking occurs when students are involved in the learning process through taking responsibility about their own learning. Classroom teaching modes, which include student in reflective thought, the exchange of ideas and opinions are the ones that will promote and outlive 
students during their learning. In the classes in which students are allowed to remain idle, lacking critical thinking and this is the behavior and the importance of teachers about their concepts on learning. The free and critical thinking can be indangered. Ideas may come to mind in different ways, with humor, sometimes even contradictory. It is part of critical thinking that sometimes come with "silent ideas" performed together with clever combinations or confusing notions. The teacher should provide students that this is a natural part of the learning process. It is also important to make clear that scorn or ridicule the individual ideas and opinions of everyone's, should not be allowed, because it creates an environment where everyone can prove a personal risk. Thinking is best formulated in a safe and indangered environment, where ideas are respected and where students are highly motivated to engage actively in critical thinking.

\subsection{Active involvement}

Michael Csiksentmihali (1975) demonstrated that when students are actively engaged in the learning process, at an appropriate level challenging, they greatly express satisfaction for inclusion and increase the capacity for judgment and understanding. Students can fully understand that when they are devoted to the lesson with fully energies and even success, they have the required goals. The exchange of opinions and ideas is a disciplined behavior. It requires the exchanger (the one that participates in conjunction with a partner, providing auxiliary joint elaboration of a thought, experience, etc., That short, from now on we will call exchange) to end something for the sake of others. From parents, it is taught to young children as an important social and survival skill.

However, children can accept the idea of assistance or exchange, not because their parents expect it, but because they fail to see it as a substantial ransom exchange. They understand that the end of something (a job started together) will be achieved and obtained valuables when students are set to exchange views and ideas. The exchange of beliefs, ideas and opinions may be at risk. He asks students to tell yourself and others, as thinkers and persuasive, that are capable of great thoughts and avoidance of errors. Educating every man in this way determines the learning community, of which we educate everyone.

\section{Research Methods}

The methodology used in this paper reveals the role and importance of factors affecting the correct application of research-based learning and in accordance with the level of competence and the level of their impact on student outcomes.

To determine these factors were studied and interpreted the factors that have left their mark on the structure, cultural level and global awareness of children, such as the turnover of the demographic associated with exile from rural to urban areas, in the capacity of our educational institutions to cope with new situations etc .. The facilities, classrooms where learning takes place, not the high number of students in classrooms and school texts for the students to develop the class appropriately, are all factors that influence the acquisition of teaching methods where the student is centered.

To accomplish this work are used these methods:

- discussions with school principals, teachers of elementary and secondary education, pupils and parents,

- surveys, school surveys, consultations and free discussions,

- participation in internal training school.

Also, besides the use of a broad contemporary literature in the field of teaching methods, there are researched materials by interviewing students, parents and teachers as well as becoming survey with them. Served as primary sources, interviews, observations, questionnaires and surveys that are structured and semi-structured. I was focused especially on the problems that arise during teaching. Method of conversation with old teachers, and with them who are new to the profession, conversations with students of different classes on the usefulness of the approach centered teacher and student and surveys for this problem, I was given the opportunity to improve performance continuously by enriching it with necessary elements of the study. To determine these factors were taken into analysis of records and surveys to teachers and schoolchildren laid and prepared some questions and hypotheses research.

\subsection{Research questions and hypotheses}

This study was conducted on the basis of these research questions and hypotheses.

$>$ Questions Research

1. What are some of the most common method used by teachers and when is the teacher-centered method as well as the student-centered used? 
2. When the students are more active and focused, to which method, and when the students result is higher, when only the teacher explains, or when the class is organized?

3. Are classrooms and textbooks appropriate for the students to develop the class?

Hypotheses

1. Teachers use modern methods to the student during their work in the classroom.

2. Student-centered teaching is more effective and more productive than it centered teacher.

3. Curricula and textbooks are suitable for the development of the learning process in an appropriate manner, based on the implementation of modern methods and student-centered teaching.

\subsection{Population and sampling}

As for the students, there were surveyed a total of 200 students, specifically, four classes in compulsory education from fifth grade to ninth grade, so about 100 students, and 100 students in three classes of secondary education, particularly from the high school, who were part of the survey and our observations. In this study was independently completed the survey in the form of a structured questionnaire with the same items in accordance with the characteristics fit and groups. On the basis of these questions were developed measurement instruments. Later research questions and hypotheses were associated with the determination of dependent variables and independent model of statistical analysis and sample appropriately.

\section{Analysis Results}

\subsection{Data Collection}

During my work on this paper, I have managed to collect data and evidence from observations and assessments carried out in the respective schools. Specifically, there are special hour lesson followed focusing particularly on some of the most effective ways and methods to determine the quality of teaching. Many teachers in the classroom use different ways to discuss. Usually it is the teacher who is at the center of discussions that takes place during teaching. The teacher asks and students answer questions. The teacher may refer to different students while he remains at the center of discussion. There are also cases where the discussions with the student in center, students are those who lead the discussion. A student takes the role of leader, who leads the group discussion, but the discussion then derived from one student to another. In this method, the teacher is an observer. Teacher takes notes during the discussion for later use data in evaluating the performance of students and reference materials in the next presentation. In discussing the students in class, discussion groups formed by 5 to 8 students. The atmosphere of the discussion where the center is the pupil should be an environment where democracy prevails, where students are free to express their opinions without fear.The teachers, who have a major role in teaching should be competent in possession of teaching methodology, which means:

- To recognize and possess the variety of methods, techniques and as procedures, teaching.

- To know how to use these methods and progress in adaptation to the needs of students.

- To determine when he should work with the entire class, with groups of students and special students.

- To recognize the difficulties of student learning and specific needs of their learning.

- To select and use a variety of teaching resources including all chronology information.

- To support students to focus and to adapt to link the subject.

During my observations it was concluded that the explanation occupies a greater percentage in comparison with the methods of discussion. It turns out that $60 \%$ of the class of sound explanation, versus $40 \%$ who take the discussion. 


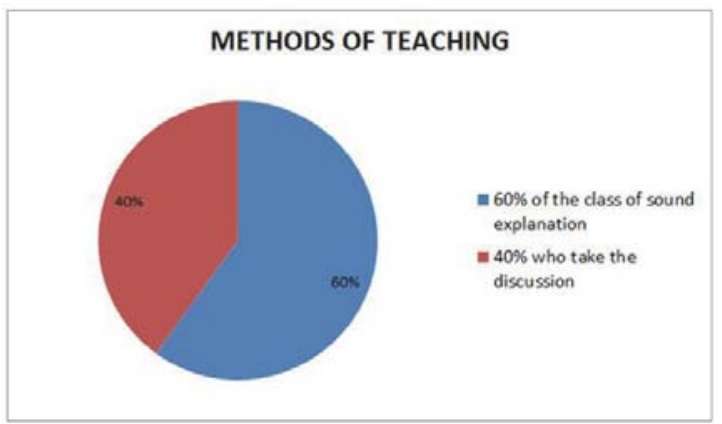

Another phenomenon is also evident in the survey environment in which it takes place in the class. It is very important for the class to be a friendly place. Classroom environment influences the success of the students is the most important criterion to develop and disclose their sentiment. It is the responsibility of teachers to create an appropriate atmosphere in the classroom. The teacher should use the personal pronoun "we" instead of "I", in order that students will feel that the teacher works with them. This helps the teacher to establish positive attitudes about teacher-student relationship, student-student, which will create a climate of emotional support, so that students learn to respect all of the individuals and their ideas. Each group should help each other to develop their own ideas.

To the teachers surveyed found that they generally take care to create a suitable environment for their students. Unfortunately classes in our country consist of a large number of students and teachers when discussing led realizes implements the Socratic method. To achieve a fruitful discussion as in the classroom and in fulfillment of the objectives set by them, teachers follow some of the following steps:

- Select some generalizations that should be learned by students.

- Provide students with information that obtained through the explanation, texts or various techniques passed on new information.

- Teachers use research questions which are served for guiding the students towards the issuance of principles and generalizations from the information that is given.

Asked about the number of methods, techniques or strategies used within one hour of instruction, $58 \%$ of teachers think that implement such usually 3, and 24\% implement 4 methods. A small percentage, 7\%, 5 teachers implement teaching methods within an hour. Number of methods and techniques applied within an hour lesson, mainly depend on the structure of the class. Usually when you use these methods you reach in provided conclusions, but it happens and often reach in unforeseen conclusions. The teacher in the implementation of this method, repeatedly asked them questions that encourage students' thinking at a high level or better known as critical thinking and aimed to lead the students in reaching conclusions, generalizations, which teacher has set as goals since the beginning of learning.

\subsection{In relation to the research questions posed in this paper that:}

\subsubsection{What are some of the most common method used by teachers and the teacher-centered methods and student- centered it?}

The basic question on which this study is the question raised above the level of impact of the application of the teaching methods in the teaching process. Based on this question was submitted and the first hypothesis:

\subsubsection{H.1 Teachers use modern methods to the student center during their work in the classroom.}

For confirmation of this hypothesis they were reviewed and analyzed the data of teachers and students as well as surveys conducted by them. During the discussions, surveys and the results of the questionnaire results that teachers, supported by information technology and communication, nowadays, use the most modern methods with traditional comparisation. They watch student-centered methods as effective because the realization of the objectives achieved in a higher mass and through their students come to acquire better knowledge of the data. Often they do a combination of these methods by remaining at the theoretical level using methods and there is a kink in the practice of these methods, which is as much scientific and professional. In most cases the teacher uses the method offered as a template not given 
to whom is addressed both in terms of cognitive, physical and emotional. There is a superficiality of knowledge of the child's stages of growth, attached it with only theoretical knowledge of teaching methods, create student-centered methods remain as beautiful models diaries. Namely processed results are presented through graphs below:

$85 \%$ of teachers surveyed prefer contemporary teaching methods, versus $15 \%$ who still have a tendency to use traditional methods.

\section{Chart No. 1}

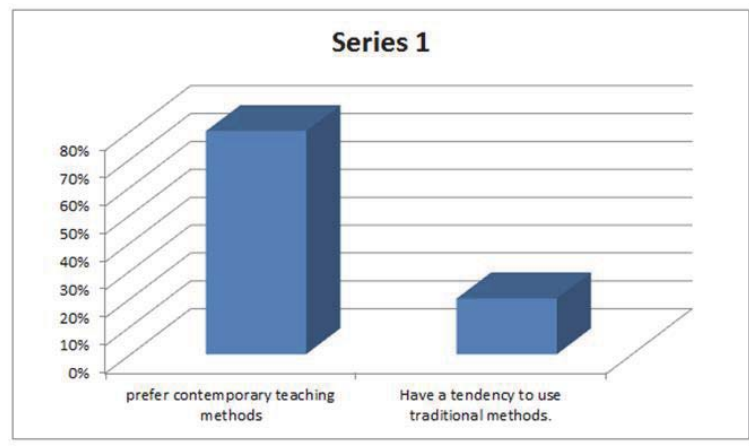

\section{Chart no. 2}

$60 \%$ of teachers say that the school year using modern methods of above $65 \%$.

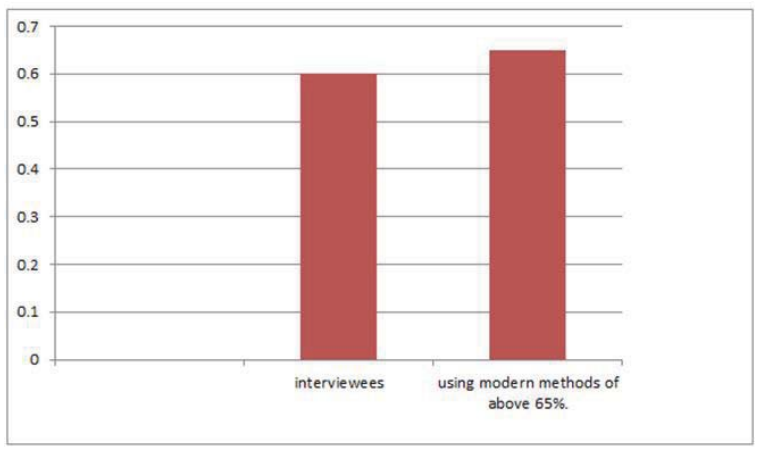

Report the use of traditional and contemporary methods not related to the age of teachers. We are not talking about traditional teacher started from the age that they have, as not all teachers new to the profession can say that he is definitely contemporary as teachers. Documentation of teachers (annual learning plans and their diaries) and classes observations point to a combination of contemporary and traditional methods. However, preference or inclination to have a philosophy teacher to a method of learning, neither is liberated from one or another of them. There is no absolute separation between traditional and contemporary.

Today, when all classes of pre-university work with textbooks selected by the teachers from the alternative list, methods to the student center is prevalent, but it is wrong to indeed pursue two other methods, it centered teacher, and she centered text have not no place, no value. The structure of alternative texts, based on the new curriculum and in accordance with the new programs, it significantly facilitates teachers and preparatory work directly with students in class. Categories learning lines and the teaching staff or skills to breathe properly when a master teacher puts the student in the class level, he builds and implements classes standards of achievement. I think the problem should not be admitted as a teacher if the teacher knows or does not know the modern methods and uses or does not use them during class. The center of gravity remains in the realization of the roles of actors class. For example, there is no value in Venin diagram techniques, when the teacher "intervenes" in meeting its student wears clothing. Or, where can stay the value of 
technology "clusters" (Tree of thought,) when the teacher "adds" to those who say the students. So, we need orientation of teachers to the principle: "Talk less, listen more" if I accept that this principle governs the use of the time report that the teacher uses the time that was left to students during class.

Teachers today recognize student-centered learning and implement planning strategies, methods and techniques depending on the structure of the class, but the information that follows the teaching unit. In the completed questionnaires, teachers list a large number of methods of teaching techniques, especially such related to critical thinking. Their list is so long that not a few teachers, group some techniques to methods, or some of them name the traditional methods. Without excluding the possibility of confusion from teachers, the time factor has already done its work. On the right, a teacher who does work in groups of more than 15 years, will call it a traditional practice. But any strategy, method or technique, modern and effective however, shall not give his teachers' expectations if it is not planned and not used in view of the objectives of the lesson. So methods are the starting point to targets. When objectives are well defined when they are real and measurable, pave the way for interactive teaching methods and weaving lessons own independent work of the students with small groups.

The teachers, who have a major role in teaching should be competent in possession of teaching methodology, which means:

- Recognize and methods own diversity, and its exam techniques, teaching.

- Know how to use these methods and progress in adaptation to the needs of students.

- Determine when to work with the entire class, to groups of students and special students.

- To recognize the difficulties of student learning and specific needs of their learning.

- To select and use a variety of teaching resources including information tecnology.

- To support students to focus and to adapt to link the subject.

The goal is to note practically it is wrong, because there is always room for improvement. Opportunities for improvements start right from the identification of the real problems, ranging from the practical application of that theory guides, adapting always environment psychosocial our schools, and always stressed the great importance that teachers prepare their professional and passion for the mission they have undertaken.

\subsubsection{When the students are more active and focused, to which method, and when the result of higher student when the teacher only explains, or when organizing a class on student-centered methods?}

The second question seeks to explain the use of student-centered methods and their role in the learning process.

\subsubsection{H.2 Teaching methods with the student center is more effective and more productive than it centered teacher.}

Through direct observation in professional practice, the use of more student-centered shows that in most cases confused with freedom of speech and expression in the classroom.

Teachers have remained at the theoretical level to use new methods and put a kink in the practice of these methods, which is as much scientific and professional. In most cases the teacher uses the method offered as a template not given to whom is addressed both in terms of cognitive, physical and emotional. There is a superficiality of knowledge of the child's stages of growth, attached it with only theoretical knowledge of teaching methods, create student-centered methods remain as beautiful models diaries.

It is very important recognition of cognitive psychology on development children to succeed in any form of teaching. Referring to Piaget's views, which means that:

During middle childhood, the cognitive area, significant changes occur, especially

when the child starts school. The child around the age of 7 years old enter the stage of concrete operations, according to Piaget's in this period the child develops a set of general rules or strategies to examine and interact with the world.

This stage of cognitive development of the child called "concrete" because thinking of the child is still based on what the child undertakes concrete objects or events, until the age of 11-12 years old child cannot understand the concepts important to abstract. It understood that the educational activity, or any other children of this age should be more concrete life.

In moments of conducting the research level of student placement in the center of the process by teachers, at least as mentality, it is not at the highest level.

Methods levels and student-centered techniques most commonly used are. 
Using the techniques in the student center

\begin{tabular}{|l|c|c|c|c|c|}
\hline Student-centered techniques & Never & Almost never & Neutral & Almost always & Almost always \\
\hline Brainstorming & 7,8 & 3,5 & 1,7 & 4,3 & 82,6 \\
\hline Work on (double) & 5,2 & 22,6 & 33,9 & 33,9 & 4,3 \\
\hline Learning on group & 7,8 & 40,0 & 29,6 & 20,0 & 1,7 \\
\hline Work with projects & 62,6 & 13, & 11,3 & 6,1 & 6,1 \\
\hline Problem solution by student ideas & 15,7 & 21,7 & 22,6 & 34,8 & 4,3 \\
\hline
\end{tabular}

In percentage terms used in the table showy technique used is thought Thunderstorm techniques (brainstorming). $82.6 \%$ of respondents claimed that the most useful have this technique. This technique is one of less used techniques. (project work) $62.6 \%$ of teachers say they have not ever used this technique. If we compare the percentage of teachers who implement almost any time permanently are less than any other technique $12.2 \%$ of them.

\subsubsection{Are curricula and textbooks appropriate for pupils and teachers to conduct classes in the right manner?}

This question formulates the third hypothesis of the study is.

\subsubsection{H.3 Curricula and textbooks are suitable for the development of the learning process in an appropriate manner, based on the implementation of modern methods and student-centered teaching.}

Ongoing reforms in education, the whole purpose of improvement had its negative sides. Given the desire for European integration to achieve European standards, many developments in education have been premature. Usage of internet in learning, with all the benefits that cannot be part of a massive learning because many families have not accessed the Internet. The use of other sources of information like extracurricular books and encyclopedias, and all the benefits that brings knowledge and learning are not usurping any student because of social and economic factors. Occasional change of curricula for improving brings continuing confusion in education. Difficulties were encountered in the curriculum $5+4$, where many teachers found themselves facing the fact that we must teach to a class that where teachers were not specialized and that required review and acquisition of knowledge that should be broadcast. Before this fact, teachers found themselves unprepared and "original", and even they have years of work experience in education. Diverse publications, or alternative text although were presented as a good opportunity for the teacher and to adjust the level of students' text, there were problems, because it was not taken into account for a moment that he of whom were formatted these texts, the student himself. Development of new curricula in recent years, made before the educational institutions as well as pre-university schools of high need for qualification of training teachers / future teachers to raise / to prepare them in time with the current requirements, as only cognitive and acquiring the best of these curricula could be implementing and implementing their competent. Teachers not only feel that necessary, but they were and still begin to be and are very interested in their professional growth. Broad participation and active in national seminars and local ones is one of the positive indicators. Teachers, regardless of age, have received new teaching strategies methods, unknown methods and techniques previously, moving away from traditional practices obsolete and ineffective.

Teachers are asked: Do you think that there should be changes in the curriculum of new pre- and if so, what would you wanted to change?

The responses show that: $-44.5 \%$ teachers clearly express that there should be changes in the curriculum of the 9year education. But $63.5 \%$ feel good curriculum of undergraduate education, and have welcomed the new changes.

How suitable are textbooks with which you work?

$-58.3 \%$ of teachers said that the texts which they work with are more suitable, $8.2 \%$ of them at all appropriate, and $33.3 \%$ think appropriate 


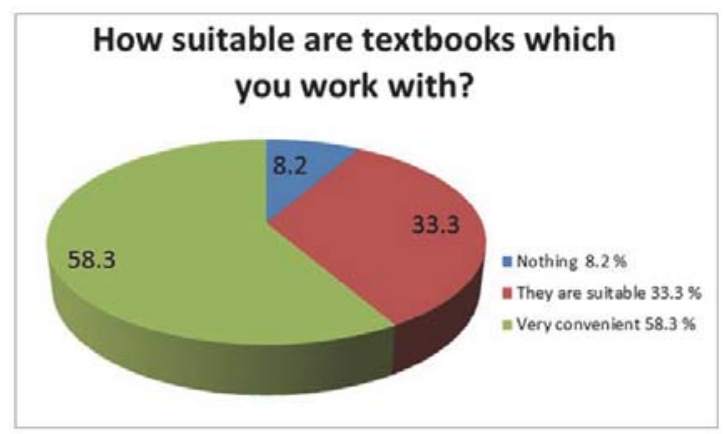

Thus teachers today is raised the demand that he answer the structure and content of the new curriculum with more comprehensive strategy. This can be achieved with the implementation of various forms of teaching work (work in pairs, group work, individual work) and various models of teaching, which put the spotlight on the students, take into account the potential and individual skills of students, do to engage all students regardless of the difficulties they have. Only the usage of alternative models, strategies varied, different forms of learning, interactive methods, individual programs, etc., facilitate the process of learning at all the students.

\section{Discussion}

For years, in the process of training and retraining of teachers are engaged the institutions and centers of state, foundations and non-governmental agencies, providing training, seminars qualification, contemporary literature, the experience and teaching of learning lesson alternatives. (Orstein, Alan C) Curriculum, the fundamentals, principles and issues, publication of ISP, Tirana, 2003, p.71). In the multitude of all these innovations, the teacher has the academic freedom to select what he prefers, what seems mostly appropriate, what can be realized more easily in terms of school and classroom where she teaches, without excluding cases of senior school education specialists and inspectors were dictated recipes teachers ready and requested use template models estimated, according to them, as the best time. Already now we can talk about effective experience in a majority of schools in all regions of the country. In addition to professional program and conducted by educational institutions in cooperation with foundations and OJQ, teachers, especially those with experience, they have himself qualification to update their practices in teaching and learning. The qualification of teachers, which remains a priority for educational institutions and other stakeholders or interest groups active in the field of education, and himself qualification, as demand continued to any teacher, when implemented effectively, serve updating professional They have impact on student achievement. Teachers see as their qualifications sources: personal libraries, school library, organize trainings RED/EO, and training from outside educational organizations. $35 \%$ of the teachers as libraries qualification and training resources from the RED/EO, while $26.5 \%$ of them, but libraries training by RED / EO, acquire and training center providing independent agencies, non-governmental.

About $70 \%$ of teachers who participated in the questionnaire have developed the necessary qualifications for modern methods.

\begin{tabular}{|c|l|c|}
\hline No. & What are the main sources of information and your training? & Total $\%$ \\
\hline 1. & Internet and personal libraries & $35 \%$ \\
\hline 2. & Trainings organized by RED / EO & 26,5 \\
\hline 3. & Training centers and agencies that provide independent, non & $20 \%$ \\
\hline
\end{tabular}

Teacher education in the country, have difficulty in using computer, so lagging behind the development of technology in this way. So the teachers who don't know the technology, it is not possible to guide students in learning with alternatives, and so today the primary school students receives information from the Internet ready and are able to analyze and synthesize information. Programs and MES guidelines recommend integrated learning, although this does not apply to genuine teaching me though is of particular importance on ease of learning, in making learning interesting and concrete. The student-centered learning, aimed at learning "doing", but with all these reforms and endless current school infrastructure in the country, highlighting the lack of teaching aids, as well as teacher training that is wishful thinking. The important factor is the teacher in teaching, training, adequately training will be the key to teaching we aim to achieve. 


\section{Conclusions}

Student-centered teaching is one of the methods that puts the learner at the center of attention and gives priority to critical thinking and the formation of the personality of students. With traditional methods, researchers and teachers have noticed the superficiality in the understanding of students and passive knowledge of all ages and classes.

Effective teaching and learning methods require the use of appropriate pedagogical and methodological. Learning "doing" has become a motto for all teachers, after convincing argument that John Dewey brought that, children should be engaged in looking to learn new ideas, he also stressed that students should be presented with real-life problems, so then we can help them to find the necessary information that will help to solve these problems in themselves.

Many teachers combine different methodologies in teaching. No method old or new, should not be served as the sole teaching. Contemporary and traditional methods aimed at the same thing in education, namely the improvement of teaching, student achievement elevation, forming good citizens and more productive and improve society.

Schools and teachers should seek a middle way, an elusive and abstract concept, where we do not have the extreme emphasis of matter or students. A teaching is all what we conceptually and economically need, serving student learning.

The purpose of the change of methodology and education in general through reforms of successive, it is very important for how comes at the right time for assimilation, because a society can assimilate at once the views of extreme brings "new" and again to be an democratic education. The type of society in which they develop significantly is reflected in our educational system.

We think it should be done in terms of training of teachers and in improving curriculum development towards greater space for the application of research, not only vision, but also as a basic element of content. A precondition for the success of the application of the mentioned methods will be to the level of democratization of relations curriculum teacher-student. At this level trinomial the teacher says his level in taking the role as teacher and student coach said of abilities and competencies for self-directed learning.

As suggestions and main tasks of this paper we can recommend:

- Avoid continuous reforms overlapping and confusing in this way the goals and primary and secondary objectives.

- Raising the standard of learning.

- Improving the initial and continuing teacher training.

- Increasing responsibility of the school inspectors for quality control, not only for administrative purposes.

- Increasing motivation of teachers as financial incentives, new perspectives in his professional career, improved working conditions etc.

- Community involvement in the problems of education, parents and intellectuals to give their opinion and contribute to the improvement of teaching.

- Coherence and comprehensiveness of all schools, at all levels in every town or village in training programs for innovation in our education.

\section{References}

AEDP. (1998). "Study everything, the reason the first place" (Symposium). Tirana.

CDE. 2005 "Interactive teaching and learning", for grades 6-12. Models for the development of critical thinking of students.

CDE. "Strategy of teaching and learning for grades thinkers".

Discipline Without Stress, Punishments or Rewards. Marshall, Dr. Marvin (2001)

Open Society Foundation Soros. Education Development Project in Albania. 1997.

Gootman, Marilyn E. The caring teacher's guide to discipline: Helping students learn self-control, Responsibility, and respect, K-6. 2008

Group of authors .AEDP, 1999. Tirana.

Group of authors. (2002) "Teaching". Tirana (2002)

Group of authors. (2001). When education would bring the soul. Tirana .. (2001).

Gardner, Howard. (2003). "Uneducated mind." Tirana, Group of authors. (1986).

G Rose, M, Karaguni, discussion that solves the problem, methodology of geography. Erik

Haliti, Sefik. In search of reform pedagogy. Crown, 2007.

Jackson's Class Organization website Blog: Tips for Better Classroom Management

Kraja, M. 2009. Education Tirana.

Kraja, Musa. Tirana Education implemented ... .. (1995).

Kraja, Musa. (2008) Learning Strategies. Tirana. (2008) 
Karaj, TH. Tiranë 2010. "Child development psychology." Journal: Teacher, Nr.9.November 2011.

The curriculum, the fundamentals, principles and problems. Tirana: ISP. CDE. (2008).

Llambiri, S. 2007. Abandoning the secret minimum necessary objectives for students

Mialaret, G.1995, Education. Institute of Pedagogical Studies. Series "Rieden" no. 1/2.

Moses B. Teaching and Learning .For grades 1-5 Pegi, 2005.

Moses, B. Methods teaching. Pegi Tirana 2003.

Models for successful teaching. Tirana. Group of authors. (1995).

Interactive Teaching and Learning - Models for the development of critical thinking, Tirana. (2005)

Models for the development of critical thinking (social sciences for grades 6-12). Tirana. QTKA. (2005).

Muka, Petrit. Education. Tirana. Muka, Petrit. (1995).

MES. (2012) Pre-university curriculum framework. (Draft) MAS 2012

Pedagogical magazines, no. 10, November 2010

Pedagogical magazines, No. 7 October, 2011

Learning objectives and model A - 94. Tirana. Orstein, Alan C. (2003).

Zylfiu, Niyazi. "Office textbooks and teaching aids ", Pristina, 1985.

Guideline, Critik and development of creative thinking, AEDP 2000

Texts of teacher - Models 